University of Warwick institutional repository

This paper is made available online in accordance with

publisher policies. Please scroll down to view the document itself. Please refer to the repository record for this item and our policy information available from the repository home page for further information.

To see the final version of this paper please visit the publisher's website. Access to the published version may require a subscription.

Author(s): Fernando E. Vegaa, Mark S. Goettelb, Meredith Blackwellc, David Chandlerd, Mark A. Jacksone, Siegfried Kellerf, Masanori Koikeg, Nguya K. Manianiah, Arnulfo Monzóni, Bonnie H. Ownleyj, Judith K. Pellk, Drauzio E.N. Rangell and Helen E. Roy

Article Title: Fungal entomopathogens: new insights on their ecology Year of publication: 2009 Link to published version: http://dx.doi.org/10.1016/j.funeco.2009.05.001

Publisher statement: none 
Fungal Ecology
Address Correspondence to:

Fernando E. Vega

Sustainable Perennial Crops Lab.

USDA, ARS, Bldg. 001, BARC-West

Beltsville, Maryland 20705

Telephone: 301-504-5101

Fax: 301-504-1998

Email: Fernando.Vega@ars.usda.gov

\section{Fungal entomopathogens: new insights on their ecology ${ }^{\dagger}$}

Fernando E. VEGA ${ }^{\mathrm{a},{ }^{*}}$, Mark S. GOETTEL ${ }^{\mathrm{b}}$, Meredith BLACKWELL ${ }^{\mathrm{c}}$, David CHANDLER $^{\mathrm{d}}$, Mark A. JACKSON ${ }^{\mathrm{e}}$, Siegfried KELLER ${ }^{\mathrm{f}}$, Masanori KOIKE ${ }^{\mathrm{g}}$, Nguya K. MANIANIA ${ }^{\mathrm{h}}$, Arnulfo MONZÓN ${ }^{\mathrm{i}}$, Bonnie H. OWNLEY ${ }^{\mathrm{j}}$, Judith K. PELL ${ }^{\mathrm{k}}$, Drauzio E.N. RANGEL ${ }^{1}$, Helen E. ROY ${ }^{\mathrm{m}}$

${ }^{a}$ Sustainable Perennial Crops Laboratory, United States Department of Agriculture, Agricultural Research Service, Building 001, Beltsville, Maryland 20705 USA

\footnotetext{
${ }^{\mathrm{b}}$ Agriculture and Agri-Food Canada, Lethbridge Research Centre, 5403-1 Avenue South, P. O. Box 3000, Lethbridge, Alberta, Canada T1J 4B1
}

\footnotetext{
${ }^{\mathrm{c} D e p a r t m e n t ~ o f ~ B i o l o g i c a l ~ S c i e n c e s, ~ L o u i s i a n a ~ S t a t e ~ U n i v e r s i t y, ~ B a t o n ~ R o u g e, ~ L o u i s i a n a ~}$ 70803 USA

${ }^{\mathrm{d}}$ Warwick HRI, University of Warwick, Wellesbourne, Warwick, CV35 9EF, United Kingdom
} 
${ }^{\mathrm{e} B i o a c t i v e ~ A g e n t s ~ R e s e a r c h ~ U n i t, ~ N a t i o n a l ~ C e n t e r ~ f o r ~ A g r i c u l t u r a l ~ U t i l i z a t i o n ~ R e s e a r c h, ~}$ United States Department of Agriculture, Agricultural Research Service, 1815 N. University St., Peoria, Illinois 61604 USA

${ }^{\mathrm{f}}$ Rheinweg 14, CH-8264 Eschenz, Switzerland

${ }^{\mathrm{g}}$ Department of Agro-environmental Science, Obihiro University of Agriculture and Veterinary Medicine, Obihiro, Hokkaido 080-8555, Japan

${ }^{\mathrm{h}}$ International Centre of Insect Physiology and Ecology, Nairobi, P. O. Box 30772-00100 GPO, Nairobi, Kenya

i Departamento de Protección Agrícola y Forestal, Universidad Nacional Agraria, Apdo. 453, Managua, Nicaragua

${ }^{\mathrm{j}}$ Department of Entomology and Plant Pathology, 205 Ellington Plant Sciences, The University of Tennessee, Knoxville, Tennessee 37996-4560 USA

${ }^{k}$ Plant and Invertebrate Ecology Department, Rothamsted Research, Harpenden, Hertfordshire AL5 2JQ, United Kingdom 
${ }^{l}$ Instituto de Pesquisa e Desenvolvimiento, Universidade do Vale do Paraíba, São Jose dos Campos, SP 12244-000, Brazil

${ }^{\mathrm{m}}$ Biological Records Centre, NERC Centre for Ecology and Hydrology - Wallingford , Crowmarsh Gifford, Oxfordshire, OX10 8BB, United Kingdom

$\dagger$ This paper presents the discussions and conclusions reached at a conference entitled Insect pathogenic fungi in sustainable agriculture: use against insects and beyond held at The Rockefeller Foundation Bellagio Study and Conference Center, in Bellagio, Italy, June 23-27, 2008.

* Corresponding author. Tel.: +1 301-504-5101; fax: +1 301-504-1998

E-mail address: Fernando.Vega@ars.usda.gov 


\begin{abstract}
An important mechanism for insect pest control should be the use of fungal entomopathogens. Even though these organisms have been studied for more than 100 years, their effective use in the field remains elusive. Recently, however, it has been discovered that many of these entomopathogenic fungi play additional roles in nature. They are endophytes, antagonists of plant pathogens, associates with the rhizosphere, and possibly even plant growth promoting agents. These findings indicate that the ecological role of these fungi in the environment is not fully understood and limits our ability to employ them successfully for pest management. In this paper, we review the recently discovered roles played by many entomopathogenic fungi and propose new research strategies focused on alternate uses for these fungi. It seems likely that these agents can be used in multiple roles in protecting plants from pests and diseases and at the same time promoting plant growth.
\end{abstract}

Keywords: Beauveria, biological control, ecology, endophytes, Lecanicillium, Metarhizium 


\section{Introduction}

Global interdependence of markets for agricultural products have increasingly brought to the forefront the need to develop agricultural practices that mitigate adverse effects on the environment and that result in products that are safe for human consumption. One major constraint to increased agricultural production is yield losses caused by insects, plant diseases, and weeds. These losses account for $40 \%$ of potential production (Thacker 2002) and despite a marked increase in pesticide use, crop losses have remained relatively constant (Oerke 2006).

Since the late 1940’s, insect pest control has relied mostly on chemical insecticides, although in many industrialized nations, pest management strategies have been shifting to the use of transgenic plants expressing particular traits such as resistance to insect, fungi, herbicide, or viruses. However, the replacement of chemicals with transgenic plants does not represent a fundamental change in approach. In reality, it is a “like-for-like” replacement in which the tools are different but the "silver bullet” strategy is the same (Lewis et al 1997; Welsh et al. 2002). A true paradigm shift would be a change from a dependence on chemicals to a total system approach (see Lewis et al. 1997) or to ecological engineering (see Gurr et al. 2004a, b). A basic component of both approaches is a better understanding of the various ecological components in an ecosystem, including biological control agents. Among these, entomopathogenic fungi have been traditionally considered as important mortality factors for insects, but recent studies discussed below have shown that they have diverse and unexpected roles. Understanding the nature of these interactions could facilitate more effective exploitation 
of entomopathogenic fungi for pest biocontrol strategies throughout the world, including countries where the use of other strategies might not be affordable.

The earliest studies with entomopathogenic fungi occurred in the early1800's and concentrated on developing ways of managing diseases that were devastating the silkworm industry in France. Agostino Bassi (1773-1856) demonstrated that Beauveria bassiana (as Botrytis bassiana) was the infectious agent causing what was then known as the muscardine disease of silkworms. The stimulus for the idea of using fungal insect pathogens to manage pest insects came largely from the ensuing silkworm-disease studies, after finding that the fungus also infected other insects (Audoin 1837). Subsequently, Pasteur (1874) and LeConte (1874) suggested that fungi could be used against insects. In Russia, Elie Metchnikoff (1845-1916) conducted studies on an insect disease of wheat cockchafers that he called green muscardine, and he identified the infecting agent as Entomopthora anisopliae (= Metarhizium anisopliae). This fungus was mass-produced by Krassilstick (1888) and used in the field against the sugar-beet weevil.

However, the discovery and use of chemical insecticides in the 1940’s overshadowed the potential of entomopathogenic fungi and other microbial pest control agents, and created an inappropriate model by which the majority of microbial control agents are still judged and used, i.e. the chemical insecticides paradigm. Thus, the use of entomopathogenic fungi has not been based on an understanding of their ecology but on mistakenly applying the chemical insecticide paradigm to biological control agents and creating false expectations of chemical-like efficacy (Waage 1998). 
In 1983, a group of 23 specialists in plant and insect pathology, morphology and physiology met at The Rockefeller Foundation Bellagio Study and Conference Center in Italy to discuss Infection Processes of Fungi (Roberts \& Aist 1984). The conference was organized to afford the opportunity for in depth discussions among plant pathologists and insect pathologists. The participants recognized that there were many parallels between insect and plant pathogens as both need to invade via external waxy cuticular surfaces. In the 25 years since the 1983 meeting, major inroads have been made in understanding and manipulating the infection processes of insect pathogens, such as the discovery of the PR1 gene and its use in genetic modifications (St. Leger 2007). Recently, molecular tools such as DNA sequence analysis have led to a new phylogenetic classification of the Fungi that has challenged many of our assumptions about the relationships among entomopathogenic and other fungi. This new phylogeny is already leading to significant new insights that should allow us to better understand the ecology of fungal entomopathogens. In addition, it has been discovered recently that many entomopathogenic fungi play additional roles in nature, including their isolation as plant endophytes, antagonists of plant pathogens, beneficial rhizosphere-associates, and possibly even plant growth promoters. These findings raise two important questions: Have we been overlooking important factors in our quest to develop these microorganisms solely as biopesticides against insects? Can these agents be used in multiple roles to protect plants from insects and plant diseases and at the same time promote plant growth? Here we summarize recent findings and propose new research areas 


\section{Entomopathogenic fungi as biopesticides}

Entomopathogenic fungi are usually identified as such based on the fungal growth observed on insect cadavers. Most research on entomopathogenic fungi has been aimed at developing them as inundative biological control agents of insects, mites and ticks, despite great potential for use in conservation and classical biocontrol strategies (Butt et al. 2001; Goettel et al. 2005; Vincent et al. 2007). This is normally achieved through a strategy in which pest control relies on the action of the released agent but not on successive generations of the fungus. Under this paradigm, over 170 products have been developed based on at least 12 species of fungi (Faria \& Wraight 2007). Despite there being an estimated 700 species of entomopathogenic fungi in approximately 90 genera (Roberts \& Humber 1981), most of the commercially produced fungi are species of Beauveria, Metarhizium, Lecanicillium and Isaria that are relatively easy to mass produce. Attention has focused predominantly on the technical aspects of biopesticide development, such as mass production and formulation, and the selection of strains with rapid kill. Production requirements include reasonable cost, long-term stability, and, most importantly, consistent efficacy under field conditions. The prevalent methods involve production of diaspores (dispersal units) by induction of aerial conidiation on solid growth media, production of blastospores by yeast-like growth in liquid media or growth of hyphal biomass in liquid or solid media (Faria \& Wraight 2007).

For control of insect pests in the phylloplane, suspensions of aerial conidia including blastospores are applied in spray applications, e.g. M. anisopliae var. acridum for locust control in Africa (Langewald \& Kooyman 2007). The numerous, discrete, infective propagules provided by spore forms satisfy the requirement for complete 
coverage of the foliar surface to ensure contact and infection of the insect host. To improve dispersion, hydrophobic conidia are often formulated in oil or added to spray mixes containing wetting agents as adjuvants. Spray preparations of hydrophilic blastospores can include wetting agents as adjuvants but are generally formulated as wettable powders or water-dispersible granules. Since propagule persistence of fungi on the foliar surface is affected by solar radiation, considerable effort has focused on the protection of these entomopathogens by incorporating solar blockers and sunscreens (Inglis et al. 2001). However, to open up a wider array of biocontrol strategies there is a need to significantly improve our understanding of the ecology of entomopathogenic fungi outside of the insect host, especially fungal life history strategies and their role in the ecosystem.

A number of recent discoveries suggest that current approaches to insect control with pathogenic fungi require revision. For example, rhizosphere competence by strains of M. anisopliae is dependent on the plant community and not necessarily the presence of an insect host (Hu \& St. Leger 2002) and strains of B. bassiana exist as endophytes in various plant species and exhibit the potential for insect and plant disease suppression (Vega 2008; Ownley et al. 2008b).

\section{Arthropod-associated fungi: evolution and nutritional associations}

Entomopathogenic fungi infect their insect hosts by penetrating through the cuticle or through body openings (Tanada and Kaya 1993). They have evolved specialized mechanisms for the enzymatic degradation of the integument and for overcoming insect defense compounds. The relationships by which different fungal 
species obtain energy from their insect hosts (i.e., their econutritional mode) include biotrophy (nutrition derived only from living cells, which ceases once the cell has died), necrotrophy (utilization of dead tissues), and hemibiotrophy (initially biotrophic and then becoming necrotrophic).

Recent phylogenetic studies indicate that the ability to utilize insects as a source of nutrition has arisen more than once among fungi (Spatafora et al. 2007). Scale insects, particularly Coccidae and Aleyrodidae have the greatest diversity of fungal pathogens documented (Humber 2008); these insects occur in dense and mainly immobile populations feeding on plants. The sustained proximity between these insects, fungi and other potential hosts may provide pathogenic fungi with the opportunity to move from plant to insect and beyond. Indeed, scale insects and their pathogenic fungi provide model systems for studying the fundamental aspects of host-fungal pathogen interactions. Fungi within the genus Hypocrella (Clavicipitaceae) form small stromata utilizing the nutrients available from one to a few scale insects under each stroma. However, a few Hypocrella species produce gigantic stromata (Hywel-Jones \& Samuels 1998), and these can only form with sustained nutrition from the plant after the insect host is destroyed. This is an extreme example of the nutritional adaptability that some insect pathogenic fungi exhibit, but it also highlights the diversity of nutritional modes and the ability of entomopathogenic fungi to switch between them.

A critical question is whether species of Metarhizium, Beauveria, Lecanicillium and Isaria (Luangsa-ard et al. 2005; Sung et al. 2007) function in nature as ecologically obligate insect parasites or make use of additional sources of nutrition. Meyling \& Eilenberg (2007) considered Beauveria and Metarhizium to function primarily as insect 
parasites but did not discount the possibility of additional nutritional modes. Insect parasitism by these species is common in nature (Ormond et al. 2006; Meyling \& Eilenberg 2007), but there is increasing evidence that they exhibit a more dynamic life history pattern than previously thought. Based on the abundance of entomopathogenic fungi obtained from the surface of 1,700 individual arthropods captured in aspendominated woodlands in western Canada (B. bassiana represented one-quarter of all isolates), it appears that entomopathogens are common components of the surface mycota of arthropods and are not necessarily restricted to diseased insects (Greif \& Currah 2007). There is also increasing evidence that Beauveria, Metarhizium and related genera can act as mycoparasites and plant endophytes, as well as interact with plant roots (see below). Moreover Beauveria and Metarhizium may have evolved subtle ecological adaptations to insect parasitism in the soil that we are yet to discover and, central to this, is the influence of the plant (see below).

Entomopathogenic fungi exhibit a diverse array of adaptations to insect parasitism. These include the general ability to overcome insect immune defenses and obtain nutrition from insects but also less well-studied behavioral responses (Roy et al. 2006). Host-altered behavior by some fungi has been demonstrated (e.g., summit disease, in which infected insects exhibit climbing behavior), but there are considerably fewer examples with hypocrealean-infected insects than in entomophthoralean-infected ones (Roy et al. 2006). However, we would caution against concluding that the scarcity of these adaptations in the entomopathogenic Hypocreales is evidence that these fungi are not highly specialized insect parasites, because much more basic ecological research is required. Behavioral avoidance of entomopathogenic fungi also has been reported for 
various insects: B. bassiana is avoided by Anthocoris nemorum (Meyling \& Pell 2006) and C. septempunctata (Ormond et al. in prep.), while Coptotermes lacteus avoids $M$. anisopliae (Staples \& Milner 2000). Avoidance indicates recognition of the fungus by the insect, although the specific mechanism for avoidance is not known.

A major handicap in the understanding of the ecology of entomopathogenic fungi has been a lack of phylogenetic information to explain the history of the interactions. Phylogenetic classifications based on DNA analysis has helped to improve and stabilize our understanding of fungal relationships (Blackwell et al. 2006, Hibbett et al. 2007). Phylogenetic studies have been important to understand insect fungi. For example, asexual fungi can now be placed among their nearest sexual relatives, and previously used terms such as Deuteromycota as a taxon have been abandoned completely. Insect parasites in the Hypocreales have been discovered to have convergent morphologies and moreover, different histories as symbionts. New taxa and lineages certainly will be added to the classification, because fungi are still under sampled in phylogenetic studies and, in fact, poorly known overall, but the additions will serve to test the classification as it continues to develop. The tree diagram (Fig. 1) shows the fungal phyla in the new classification.

The acquisition of a phylogeny allows us to hypothesize not only evolutionary patterns of organisms depicted in a phylogenetic tree, but also to predict traits based on relationships (Spatafora et al. 2007). We can determine if selection for certain morphological or physiological features, such as nutritional preferences, occurred in a lineage, and estimate fungal divergence times based on increasing knowledge of DNA divergence rates and the accuracy of fossil calibration points (Taylor \& Berbee 2006). It 
also is possible to compare phylogenies of two groups of ecologically associated organisms in order to determine their mutual evolutionary history.

Fungi exhibit two patterns of historical host associations. In a few cases patterns of coevolution can be identified (Currie 2003, Little and Currie 2008), but more often a pattern of host switching is evident. Although host switching is common among fungi, there have been relatively few studies of the phenomenon using taxon sampling designed to test the hypothesis. A study of Hypocreales, which contains fungi with diverse nutritional modes (insect, fungus, and plant parasites, woody plant saprobes and yeastlike symbionts) is an exception. Spatafora et al. (2007) used phylogenetic analysis and ancestral character state reconstruction to examine the origin of the nutritional modes of the large monophyletic group. The study examined 54 strains of Clavicipitaceae (s.l.) and 13 other isolates in Hypocreales. Analysis of six DNA loci indicated at least six interkingdom shifts had occurred among taxa in three distinct clades of fungal, plant and animal parasites (Fig. 2). The "traditional" Clavicipitaceae (s.l.) have been revised to reflect the new phylogenetic findings, and two new families and several new generic taxa, replace some long-established names in the newly defined monophyletic groups (Sung et al. 2007; http://cordyceps.us). It is clear from the study that members of Hypocreales arose from plant parasitic ancestors, although the nutritional mode of more immediate ancestors is sometimes ambiguous. Based on the phylogeny, Spatafora et al. (2007) concluded that Clavicipitaceae (s.l.) comprised a paraphyletic group and rejected the monophyly of Cordyceps (s.l.). Three lineages (A= Clavicipitaceae: Hypocrella, Regiocrella, Metacordyceps, Torrubiella s.l.; B= Ophiocordycipitaceae: Elaphocordyceps, Ophiocordyceps, Torrubiella s.l.; and C= Cordycipitaceae: 
Ascopolyporus, Cordyceps s.s., Hyperdermium, Torrubiella s.s.) contained taxa previously included in Cordyceps (s.l.). Plant, animal and fungus-based nutritional modes are found among two of the clades (Clavicipitaceae and Cordycipitaceae), while Ophiocordycipitaceae lacked plant associates in their study, but see below, Case Studies). Clavicipitaceae and Ophiocordycipitaceae were placed as sister taxa derived from a most recent lineage of insect parasites with the previous nutritional mode ambiguous. In the primarily animal-associated clade, Ophiocordycipitaceae, an unusual nutritional shift away from animal to hypogeous ascomycete hosts occurred in the lineage. Shifts away from parasitism apparently are rare, but within Ophiocordycipitaceae, yeast-like obligate symbionts of plant hoppers (YLS) appear to be derived from among insect parasites (Jones et al. 2000). The remarkable shift from necrotrophic parasite to obligate symbiont that is involved in sterol and nitrogen metabolism is one that calls for additional study.

Jumps to new hosts among organisms closely associated in a common habitat has been referred to as the "host habitat hypothesis" (see Nikoh \& Fukatsu 2000). This hypothesis has been put forth to explain shifts to distantly related hosts of Hypocreales (Nikoh \& Fukatsu 2000; Spatafora et al. 2007). There are several examples of extreme host shifts among members of Hypocreales (Fig. 2). Ophiocordycipitaceae that infect larval and pupal arthropod hosts in soil are the closest relatives of parasites of hypogeous fungi; species of Clavicipitaceae associated with hemipteran insect parasites have as their closest relative species with endophytic life styles. Additional detailed sampling will be profitable for the continuing development of hypotheses on the origin of fungal host associations and subsequent host shifts. 


\section{Additional roles for entomopathogenic fungi in nature}

Various unexpected roles have been reported for fungal entomopathogens, including their presence as fungal endophytes, plant disease antagonists, rhizosphere colonizers and plant growth promoting fungi. These are discussed below, and detailed case studies are presented in an on-line Appendix.

\section{Fungal endophytes}

Endophytes infect above ground internal plant tissues without causing symptoms, and they are garnering increased attention because they are ubiquitous and have immense diversity and varied roles (see Saikkonen et al. 2006; Arnold \& Lutzoni 2007). Some fungal endophytes protect host plants against pathogens and herbivores (Arnold et al. 2003; Schulz \& Boyle 2005; Arnold \& Lewis 2005; Rudgers et al. 2007), and many fungi traditionally known as insect pathogens have been isolated as endophytes, including species of Acremonium, Beauveria, Cladosporium, Clonostachys and Isaria (Vega 2008; Vega et al. 2008).

\section{Plant disease antagonists}

In plant pathology, biological control most often refers to the use of natural or modified fungi or bacteria that are antagonists of plant pathogens. The term antagonism refers to a generalized mechanism by which the survival or disease-causing activity of a pathogen is reduced. Several mechanisms of antagonism against plant pathogens have been identified. These include production of various metabolites, such as antibiotics, bioactive volatile compounds (e.g., ammonia, hydrogen cyanide, alkyl pyrones, alcohols, 
acids, esters, ketones and lipids) and enzymes. Other mechanisms are competition (for niche or infection site, carbon, nitrogen or various minerals), parasitism, hypovirulence, induced systemic resistance and increased plant growth response (Ownley \& Windham 2007).

In addition to activity against insects, there is substantial evidence that some entomopathogenic fungi, including Beauveria bassiana (Ownley et al. 2004; Ownley et al. 2008a, 2008b) and species of Lecanicillium (Askary et al. 1998; Benhamou \& Brodeur 2000, 2001; Kim et al. 2007, 2008) also are antagonistic to plant pathogens. Mechanisms of antagonism utilized by B. bassiana may include antibiosis (Renwick et al. 1991; Reisenzein \& Tiefenbrunner 1997; Bark et al. 1996; Veseley \& Koubova 1994; Lee et al. 1999), competition (Ownley et al. 2004) and induced systemic resistance (Griffin et al. 2006; Ownley et al. 2008b). In addition to utilizing mechanisms of induced systemic resistance and antibiosis (Benhamou \& Brodeur 2000, 2001), Lecanicillium species are parasitic on fungal plant pathogens (Askary et al. 1998).

\section{Rhizosphere colonizers and plant growth promoting fungi}

Entomopathogenic fungi in the Hypocreales are ubiquitous members of the soil microbiota. The entomopathogenic fungal species most frequently isolated from soils in temperate regions belong to the genera Beauveria, Isaria (Cordycipitaceae) and Metarhizium (Clavicipitaceae) (Meyling \& Eilenberg 2007). As an environment, soil presents opportunities and challenges to entomopathogenic fungi. It protects from damaging solar radiation and acts as a buffer against extremes of temperature and water availability (Gaugler et al. 1989; Inglis et al. 2001; Roberts \& Campbell 1977; Rangel et 
al. 2005). Furthermore, it is a habitat for many potential insect hosts, some of which occur at high densities; continuity in proximity to potential hosts is a factor in the evolution of fungal entomopathogenicity (Humber 2008). However, soil is also infused with antimicrobial metabolites secreted by microbes that can impair the ability of entomopathogenic fungi to infect their hosts. For example, Groden \& Lockwood (1991) identified a significant trend of lower mortality of Colorado potato beetle by B. bassiana with increased soil fungistasis levels. A dead or dying insect infected by an entomopathogenic fungus represents a potential source of energy for other, opportunistic soil microorganisms. Some species of hypocrealean entomopathogens produce secondary metabolites within their insect hosts that are postulated to help the fungus outcompete opportunists during the saprotrophic phase of insect utilization (Strasser et al. 2000).

Species of Beauveria and Metarhizium that have infected and killed an insect in soil produce only limited somatic growth from the fungus-infected cadaver. This has been taken as evidence that these fungi rely predominantly on the insect rather than on the soil for carbon (Inglis et al. 2001; Pereira et al. 1993; Gottwald \& Tedders 1984). However, in the rhizosphere free carbon is abundant and there is evidence that entomopathogenic fungi interact with plant roots for growth or survival (St. Leger 2008). Between 10 and $40 \%$ of carbon assimilated by a plant is transferred into the soil in the form of exudates, mucilage, sloughed root cells and lysates (Andrews \& Harris 2000; Bardgett 2005). This carbon is exploited by a diversity of saprotrophic microorganisms in the rhizosphere (Cooke \& Whipps 1993; Whipps 2001). In most cases, it is still not clear whether this is purely a one way interaction benefiting only microbial saprotrophs 
or whether a mutualistic interaction has evolved in which the plant also benefits from the provision of mineral nutrients or protection from parasites and herbivores (Singh et al. 2004). Studies on plant parasitic nematodes and their microbial antagonists have demonstrated that nematode control is greatest on roots that support the highest rhizosphere colonization of Pochonia chlamydosporia, a facultative fungal pathogen of nematodes. The extent of rhizospere colonization by $P$. chlamydosporia varies on different plant cultivars and between different isolates of the fungus (De Leij \& Kerry 1991; Bourne et al. 1996; Kerry 2000). These studies clearly demonstrate a relationship between rhizosphere competence and a functional role such as biological control. Metarhizium anisopliae increased stand density and fresh weight of field corn after conidia were applied to corn seeds prior to planting, in an attempt to reduce damage caused by wireworms (Kabaluk \& Ericsson 2007). The mechanism for this effect on yield remains unknown.

\section{A new paradigm for entomopathogenic fungi, and future research needs}

Despite the publication of approximately 7,000 papers on topics related to entomopathogenic fungi since 1983 (S. Wilzer, National Agricultural Library, pers. commun.), there is still limited success in solving agricultural problems with entomopathogenic fungi. The following proposed research areas should lead to a new paradigm for entomopathogenic fungi that should refocus our efforts and hopefully lead to exciting new findings that will bring success to the field. 


\section{Endophytes}

Associations between fungal endophytes and plants could be useful in designing studies aimed at better approaches for using entomopathogenic fungi. Many research areas need to be addressed: (1) Which specific physiological mechanisms do entomopathogenic fungi rely on to enter the plant? (2) Do these mechanisms vary when introductions are attempted via the roots, stem, leaves, or flowers? (3) Are different diaspores (e.g., conidia, blastospores, microsclerotia) better suited to infect the plant? (4) Does identity of fungal isolate influence endophyte success? Why? (5) Do isolates have different survival rates once inside the plant? Why? (6) Are entomopathogenic fungi part of the air spora, or are they acquired vertically via seeds, or through conidia present in the soil/root interphase or both? Are insects ever involved? (7) Could plants that harbor endophytic entomopathogens provide nutritional clues that could be used for improving methods of mass production? (8) How do endophytic entomopathogens affect their host plants and the insects feeding on these plants? (9) Do endophytic entomopathogens produce metabolites in planta? (10) Could insects become diseased after feeding on plants containing endophytic entomopathogens? Answers to these questions will allow for novel approaches aimed at using entomopathogenic fungi in agriculture.

\section{Plant disease antagonists}

Although the potential for biological control of plant pathogens has been clearly demonstrated with certain entomopathogenic fungi, the key to successful exploitation of these organisms in agriculture is identifying and understanding the operative mechanisms 
of biocontrol activity. New evidence suggests that B. bassiana and Lecanicillium species employ multiple mechanisms that vary with plant pathogen, but may also vary with plant host species or cultivar. In addition, efficacy will be affected by a myriad of abiotic and biotic environmental factors. Using model plant systems, profiles of global gene expression in response to endophytic or rhizosphere colonization can be examined in the absence of other variables. In addition to expected changes in expression profiles of recognized plant defense response genes, genome-wide expression arrays could reveal novel plant genes that respond to colonization by entomopathogenic fungi. Naturally occurring nonpathogenic epiphytic and endophytic microorganisms will also influence the efficacy of entomopathogenic fungi against plant pathogens. Identifying beneficial and deleterious relationships with other microorganisms may allow manipulation of agricultural systems to enhance the positive influences. Likewise, identification of abiotic factors, such as soil characteristics that enhance or inhibit biological control of soilborne plant pathogens, would allow manipulation of these factors and improvements in efficacy. Such abiotic factors may include minerals needed as cofactors for production of bioactive compounds involved in biological control mechanisms of entomopathogenic fungi. By gaining a greater understanding of all of the interacting factors related to mechanism, significant improvements in efficacy against plant pathogens with entomopathogenic fungi should be possible.

\section{Rhizosphere colonizers and plant growth promoting fungi}

Up to now, there has been little unequivocal evidence of true rhizosphere competence (growth of the fungus within the root zone utilizing plant carbon) in 
Metarhizium and related entomopathogenic fungi. The mechanism of interaction between fungus and plant root needs to be elucidated. It should be possible to examine hyphal growth within the rhizosphere using entomopathogenic fungi expressing the GFP gene (as used by Hu \& St. Leger 2002). The use of fluorescence in situ hybridization (FISH) with taxon-specific probes in combination with microautoradiography following ${ }^{14} \mathrm{CO}_{2}$ pulse labeling of a plant would also indicate whether the fungus is able to grow on rhizodeposited material (Singh et al. 2004). In vitro gene expression technologies could also be used to determine whether cell-cell signaling occurs between plant and fungus.

Studies on the interaction between soil dwelling entomopathogenic fungi and the root zone have tended to use applications of inoculum well above the levels found in natural communities. In these experiments, it is possible that the applied fungus is able to outcompete other functional groups of microbes for the duration of the experiment as a consequence of high density. It will be important, therefore, to investigate whether natural rhizosphere colonization occurs and considerably more research is needed before new strategies using entomopathogenic fungi as rhizosphere colonizers could be considered.

There are a number of critical questions relating to plant-fungus-insect associations in the soil. These center on whether plants and entomopathogenic fungi have been involved in a dynamic process of co-evolution, for example through the endophytic colonization of roots or saprotrophic growth on plant exudates. Key questions include: (1) Do plants benefit from the presence of entomopathogenic fungi in the rhizosphere, (e.g., as the parasitism of root feeding pests) and have plants evolved mechanisms that encourage the survival and development of fungi in the rhizosphere? (2) Is the 
“bodyguard” concept (van Damm et al. 2003; see below) relevant in the soil? (3) It is highly likely that insect pathogenicity evolved independently in some of the different taxa of the anamorphic ascomycetes (Spatafora et al. 2007; http://cordyceps.us/), in which case, do different phylogenetic entities of entomopathogenic fungi display different strategies with respect to their association with plants? (4) What is the role of soil dwelling entomopathogenic fungi in interactions between above ground and below ground ecosystems? (5) Are the yield increases in field corn reported by Kabaluk \& Ericsson (2007) due to rhizosphere colonization by M. anisopliae? What is the exact mechanism for the positive effects observed? Does $M$. anisopliae protect the plant against fungal pathogens that might infect the seedlings, as well as herbivores feeding on the roots? Would other entomopathogenic fungi have the same effects? Finally, (5) how does plant diversity impact fungal biodiversity at landscape and local scales, and what is its impact on natural pest control as an ecosystem service? Addressing these questions will contribute to improvements in biological control.

\section{The bodyguard hypothesis}

The bodyguard hypothesis states that plants have evolved mechanisms to favor/retain natural enemies of their herbivore pests and thereby protect themselves from damage (Elliot et al. 2000). It is unknown whether plants provide nutrients of particular value to entomopathogenic fungi, but it would seem to be an evolutionary advantage for the plant to do so.

Plants also produce semiochemicals that are induced in response to herbivoreinduced damage (Chamberlain et al. 2001). The semiochemicals are a component of the 
induced resistance mechanism of plants and act as specific cues for beneficial arthropods to detect the presence of hosts (Dicke \& Bruin 2001). There are few examples of beneficial microbial agents, such as entomopathogenic fungi, that use herbivore associated--plant derived cues to identify host presence and adapt their activity. One example, however, has been described for the aphid pathogenic entomophthoralean fungus Pandora neoaphidis. Germination of conidia is faster in the presence of herbivore-damage induced plant volatiles, although not sufficiently faster to increase aphid mortality under the experimental conditions (Baverstock et al. 2005). Most of the examples relate to volatiles produced in response to foliar damage but they also are recorded in roots (Koske 1982) as part of the pathways for induced plant resistance and therefore, are active in the soil. Although there is increasing interest in above-below ground interactions and the relationships between communities associated with roots and foliage, entomopathogenic fungi within the soil microbial fauna have not been considered in this context.

Cory \& Hoover (2006) reviewed plant-mediated effects on insect pathogen interactions with particular emphasis on interactions on the phylloplane and the role of phytochemistry and other natural enemies in modulating the efficacy of entomopathogens. Plants are thought to recruit insect parasitoids and predators as bodyguards against insect herbivores (Sabelis et al. 1999). Whether plants manipulate entomopathogenic fungi in a similar way remains to be demonstrated (Elliot et al. 2000); the use of entomopathogenic fungi as 'bodyguards' by plants would require variation in selectable plant traits influencing pathogen efficacy and increased plant fitness. Such traits are yet to be demonstrated but it is clear that insect pathogens are affected by 
tritrophic interactions and that complex multitrophic relationships do exist (Cory \& Hoover 2006).

Work by St. Leger (2008) and by Bruck (2005) demonstrated that persistence of M. anisopliae conidia is higher in the rhizosphere than in bulk soil but it remains to be seen whether this is a by-product of plant biology concerned with other life history traits or is an evolved response. Cory \& Hoover (2006) also raised the issue of whether entomopathogen populations become specialized on different host plants. There is evidence that the population structure of species of Beauveria, Isaria and Metarhizium interact with habitat type. For example, in agroecosystems in the UK, Isaria is confined mainly to hedgerows and is rare in field crops, while two of the deeply rooted clades of Beauveria differ significantly in their preference for hedgerow as opposed to open field habitats (Chandler, unpubl.). Examining whether these fungi show specialization for different host plants should be a priority for future studies.

\section{Production strategies for fungal biocontrol agents}

Both the rhizosphere and the phylloplane present unique challenges to biological control with living fungal agents. The environmental and ecological variations within agro-ecosystems have made consistent insect pest management with fungal pathogens difficult to achieve on a commercial level. The use of a generalized approach to the formulation and application of microbial biocontrol agents has, in part, led to this inconsistency in control. A more detailed understanding of the pathogen-insect ecology as well as other environmental and ecological interactions is needed to improve the consistency of control for these living microbial pest control agents. 
For insect pests of the rhizosphere, fungal biological control agents are typically applied as granules containing hyphae or spore-hyphae preparations. Granules may contain infective conidia or rely on primary growth and in situ secondary sporulation for the formation of infective conidia. The conidia-containing granules must be adequately dispersed and remain viable in the soil to insure contact with foraging insect pests. Recently, M. anisopliae was shown to be capable of producing sclerotia in liquid culture fermentation (Jaronski \& Jackson 2008; Jackson \& Jaronski in press). Sclerotia are overwintering structures formed by many plant pathogenic fungi that sporulate to produce infective conidia when environmental conditions are suitable for infection of their host plant.

The ability of $M$. anisopliae to form sclerotia may be important for rhizosphere competence following a pattern seen in phytopathogenic fungi. The use of sclerotial preparations for granular application of $M$. anisopliae in soil and the use of conidia or blastospores in foliar applications for phylloplane insects are examples of how the ecology of the fungus - insect interaction directs the production and use of appropriate infective propagules. Likewise, the use of endophytic entomopathogenic fungi for insect control will require an understanding the ecological factors that enhance the fungus's ability to become endophytic. Awareness of these ecological factors will guide the development of production and formulation technologies that deliver optimally infective fungal propagules. 


\section{Formulation of fungal propagules}

The formulation of propagules of fungal entomopathogenic fungi for use in biocontrol has been guided by the need to improve product shelf life, biocontrol efficacy, and/or the physical characteristics of the product for application (Wraight et al. 2001). Undoubtedly, these goals are often conflicted with ecological considerations. For control of insect pests of the phylloplane, spore suspensions are applied in spray applications. The numerous, discrete, infective propagules provided by spore forms satisfy the requirement for complete coverage of the foliar surface to ensure contact and infection of the insect host. Formulations that improve spore desiccation tolerance or shelf life such as cryoprotectants or oils may inhibit spore germination or intimate contact of the spore with the insect host, resulting in reduced biocontrol efficacy.

Recently, research has been initiated to analyze the surface chemistry of spores of entomopathogenic fungi, an important contribution towards understanding their ecology. For example, Isaria fumosorosea blastospores were found to have a basic, monopolar, hydrophilic surface with an isoelectric point of 3.4 (Dunlap et al. 2005). The isoelectric point is the $\mathrm{pH}$ at which a surface or compound has a neutral charge. At a pH higher than 3.4, the surface charge of $I$. fumosorosea is negative and at a more acidic $\mathrm{pH}$ the surface is positively charged. Therefore, the $\mathrm{pH}$ of the environment or of the formulation can affect the charge of the spore surface and its ability to adhere to the insect cuticle or other surfaces. Similar work on the characterization of the surface chemistry of Beauveria bassiana spore forms has also been reported (Holder et al. 2007). A directed approach to formulation for improved biocontrol efficacy should include an understanding of the fungal spore - insect surface chemistries and how they interact to 
enhance adhesion and fungal infection. Understanding how the insect pest or the microbial pathogen interacts or survives in a given ecological environment is critical in directing the use of appropriate formulations.

\section{Future prospects}

Future research on entomopathogenic fungi should focus on trying to understand the ecology of the fungi in a context that focuses on their roles as endophytes, plant disease antagonists, rhizosphere colonizers, and plant growth promoters. These areas could lead to (1) a better understanding of the disparate ecological niches occupied by entomopathogenic fungi; (2) improved deployment for better pest control; and (3) improved production and formulation to enhance their efficacy. We believe that insights gained from these studies will result in the effective use of these promising organisms as an integral part of agricultural systems throughout the world.

\section{Acknowledgements}

We wish to express our deepest appreciation to the staff of The Rockefeller Foundation Bellagio Study and Conference Center in Italy for hosting the June 2008 meeting Entomopathogenic fungi in sustainable agriculture: use against insects and beyond, organized by F. E. Vega and M. S. Goettel. It is fitting that the meeting took place in Lombardy, a region of the Italian silk industry and the home of Agostino Bassi, who discovered that the muscardine disease of silkworms was caused by a fungus that came to be named Beauveria bassiana in his honor. Special thanks to Linda Marston-Reid, Pilar Palaciá, and Laura Podio at The Rockefeller Foundation, and Susan Wilzer at the 
National Agricultural Library (USDA, ARS). We are grateful to M. Catherine Aime (Louisiana State University), L. Lacey (USDA, ARS), L. Boddy (Cardiff University), and two anonymous reviewers for comments on a previous version of this manuscript. $\mathrm{M}$. Blackwell acknowledges support from NSF-0732671. J. K. Pell is funded by the Department for Environment, Food and Rural Affairs (Defra) of the United Kingdom. Rothamsted Research is an institute of the Biotechnology and Biological Sciences Research Council (BBSRC) of the United Kingdom.

\section{References}

Andrews JH, Harris RF, 2000. The ecology and biogeography of microorganisms on plant surfaces. Annual Review of Phytopathology 38: 145-180.

Arnold AE, Mejía LC, Kyllo D, Rojas EI, Maynard Z, Robbins N, Herre EA, 2003. Fungal endophytes limit pathogen damage in a tropical tree. Proceedings of the National Academy of Sciences USA 100: 15649-15654.

Arnold AE, Lewis LC, 2005. Ecology and evolution of fungal endophytes, and their roles against insects. In: Vega FE, Blackwell M (Eds.), Insect-Fungal Associations: Ecology and Evolution. Oxford University Press, New York, pp. 74-96.

Arnold AE, Lutzoni F, 2007. Diversity and host range of foliar fungal endophytes: are tropical leaves biodiversity hotspots? Ecology 88: 541-549.

Askary H, Carrière Y, Bélanger RR, Brodeur J, 1998. Pathogenicity of the fungus Verticillium lecanii to aphids and powdery mildew. Biocontrol Science and Technology 8: $23-32$.

Audoin V, 1837. Nouvelles expériences sur la nature de la maladie contagieuse qui attaque les Vers à soie, et qu'on désigne sous le nom de Muscardine. Annales des Sciences Naturelles 8: 257-270.

Bardgett RD, 2005. The Biology of Soil: A Community and Ecosystem Approach. Oxford University Press, New York.

Bark YG, Lee DG, Kim YH, Kang SC, 1996. Antibiotic properties of an entomopathogenic fungus, Beauveria bassiana, on Fusarium oxysporum and Botrytis cinerea. Korean Journal of Plant Pathology 12: 245-250. 
Baverstock J, Elliot SL, Alderson PG, Pell JK, 2005. Response of the entomopathogenic fungus Pandora neoaphidis to aphid-induced plant volatiles. Journal of Invertebrate Pathology 89: 157-164.

Benhamou N, Brodeur J, 2000. Evidence for antibiosis and induced host defense reactions in the interaction between Verticillium lecanii and Penicillium digitatum, the causal agent of green mold. Phytopathology 90: 932-943.

Benhamou N, Brodeur J, 2001. Pre-inoculation of Ri T-DNA transformed cucumber roots with the mycoparasite, Verticillium lecanii, induces host defense reactions against Pythium ultimum infection. Physiological and Molecular Plant Pathology 58: 133-146.

Blackwell M, 1994. Minute mycological mysteries: The influence of arthropods on the lives of fungi. Mycologia 86: 1-17.

Blackwell M, Hibbett DS, Taylor JW, Spatafora JW, 2006. Research coordination networks: a phylogeny of the kingdom Fungi (Deep Hypha). Mycologia 98: 829-837.

Bourne JM, Kerry BR, de Leij FAAM, 1996. The importance of the host plant in the interaction between root-knot nematodes (Meloidogyne spp.) and the nematophagous fungus Verticillium chlamydosporium Goddard. Biocontrol Science and Technology 6: 539-548.

Bruck DJ, 2005. Ecology of Metarhizium anisopliae in soilless potting media and the rhizosphere: implications for pest management. Biological Control 32: 155-163.

Butt TM, Jackson C, Magan N (Eds.), 2001. Fungi as Biocontrol Agents: Progress, Problems, and Potential. CABI Publishing, Wallingford, United Kingdom.

Chamberlain K, Guerrieri E, Pennacchio F, Pettersson J, Pickett JA, Poppy GM, Powell W, Wadhams LJ, Woodcock CM, 2001. Can aphid-induced plant signals be transmitted aerially and through the rhizosphere? Biochemical Systematics and Ecology 10: 10631074.

Cooke RC, Whipps JM, 1993. Ecophysiology of Fungi. Wiley-Blackwell, Boston.

Cory J, Hoover K, 2006. Plant-mediated effects in insect-pathogen interactions. Trends in Ecology and Evolution 21: 278-286.

Currie C R, Wong B, Stuart AE, Schultz TR, Rehner SA, Mueller UG, Sung G-H, Spatafora JW, Straus NA, 2003. Ancient tripartite coevolution in the attine ant-microbe symbiosis. Science 299: 386-388.

De Leij FAAM, Kerry BR, 1991. The nematophagous fungus, Verticillium chlamydosporium Goddard, as a potential biological control agent for Meloidogyne arenarea (Neal) Chitwood. Revue de Nématologie 14: 157-164. 
Dicke M, Bruin J, 2001. Chemical information transfer between plants: back to the future. Biochemical Systematics and Ecology 29: 110-126.

Dunlap CA, Biresaw G, Jackson MA, 2005. Hydrophobic and electrostatic cell surface properties of blastospores of the entomopathogenic fungus Paecilomyces fumosoroseus. Colloids and Surfaces B: Biointerfaces 46:261-266.

Elliot S, Sabelis M, Janssen A, van der Geest L, Beerling E, Fransen J, 2000. Can plants use entomopathogens as bodyguards? Ecology Letters 3: 228-235.

Faria MR de, Wraight SP, 2007. Mycoinsecticides and mycoacaricides: A comprehensive list with worldwide coverage and international classification of formulation types. Biological Control 43: 237-256.

Gaugler R, Costa SD, Lashomb J, 1989. Stability and efficacy of Beauveria bassiana soil inoculations. Environmental Entomology 18: 412-417.

Goettel MS, Eilenberg J, Glare TR, 2005. Entomopathogenic fungi and their role in regulation of insect populations. In: Gilbert L, Iatrou K, Gill S (Eds.), Comprehensive Molecular Insect Science, Vol. 6. Elsevier, Boston, pp. 361-406.

Gottwald TR, Tedders WL, 1984. Colonization, transmission and longevity of Beauveria bassiana and Metarhizium anisopliae (Deuteromycotina: Hyphomycetes) on pecan weevil larvae (Coleoptera: Curculionidae) in the soil. Environmental Entomology 13: 557-560.

Greif MD, Currah RS, 2007. Patterns in the occurrence of saprophytic fungi carried by arthropods caught in traps baited with rotted wood and dung. Mycologia 99: 7-19.

Griffin MR, Ownley BH, Klingeman WE, Pereira RM, 2006. Evidence of induced systemic resistance with Beauveria bassiana against Xanthomonas in cotton. Phytopathology 96: S42.

Groden E, Lockwood JL, 1991. Effects of soil fungistasis on Beauveria bassiana and its relationship to disease incidence in the Colorado potato beetle, Leptinotarsa decemlineata, in Michigan and Rhode Island soils. Journal of Invertebrate Pathology 57: 7-16.

Gurr GM, Wratten SD, Altieri MA, 2004a. Ecological engineering: a new direction for agricultural pest management. AFBM Journal 1:28-35.

Gurr GM, Wratten SD, Altieri MA, 2004b. Ecological Engineering for Pest Management: Advances in Habitat Manipulation for Arthropods. CSIRO Publishing, Australia. 
Hibbett DS, Binder, Bischoff JF, Blackwell M, Canon PF, Eriksson OE, Huhndorf S, James T, Kirk PM, Lücking R, Lumbsch HT, Lutzoni F, Matheny PB, McLaughlin DJ, Powell MJ, Redhead S, Schoch CL, Spatafora JW, Stalpers JA, Vilgalys R, Aime MC, Aptroot A, Bauer R, Begerow D, Benny GL, Castlebury LA, Crous PW, Dai YC, Gams W, Geiser DM, Griffith GW, Gueidan C, Hawksworth DL, Hestmark G, Hosaka K, Humber RA, Hyde KD, Ironside JE, Kõljalg U, Kurtzman CP, Larsson KH, Lichtwardt R, Longcore J, Miadlikowska J, Miller A, Moncalvo JM, Mozley-Standridge S, Oberwinkler F, Parmasto E, Reeb V, Rogers JD, Roux C, Ryvarden L, Sampaio JP, Schuessler A, Sugiyama J, Thorn RG, Tibell L, Untereiner WA, Walker C, Wang Z, Weir A, Weiss M, White MM, Winka K, Yao YJ, Zhang N, 2007. A higher-level phylogenetic classification of the Fungi. Mycological Research 111: 509-547.

Holder DJ, Kirkland BH, Lewis MW, Keyhani NO, 2007. Surface characteristics of the entomopathogenic fungus Beauveria (Cordyceps) bassiana. Microbiology. 153: 34483457.

Hu G, St Leger RJ, 2002. Field studies using recombinant mycoinsecticide (Metarhizium anisopliae) reveal that it is rhizosphere competent. Applied and Environmental Microbiology 68: 6383-6387.

Humber RA, 2008. Evolution of entomopathogenicity in fungi. Journal of Invertebrate Pathology 98: 262-266.

Hywel-Jones NL, Samuels GJ, 1998. Three species of Hypocrella with large stromata pathogenic on scale insects. Mycologia 90: 36-46.

Inglis GD, Goettel MS, Butt TM, Strasser H, 2001. Use of hyphomycetous fungi for managing insect pests. In: Butt TM, Jackson CW, Magan N (Eds.), Fungi as Biocontrol Agents: Progress, Problems and Potential. CABI International/AAFC, Wallingford, United Kingdom, pp. 23-69.

Jackson MA, Jaronski ST, Production of microsclerotia of the fungal entomopathogen Metarhizium anisopliae and their potential for use as a biocontrol agent for soilinhabiting insects. Mycological Research, in press.

Jaronski, ST, Jackson MA, 2008. Efficacy of Metarhizium anisopliae microsclerotial granules. Biocontrol Science and Technology 18: 849-863.

Jones KG, Dowd PF, Blackwell, M, 1999. Polyphyletic origins of yeast-like endocytobionts from anobiid and cerambycid beetles. Mycological Research 103: 542546.

Kabaluk JT, Ericsson JD, 2007. Metarhizium anisopliae seed treatment increases yield of field corn when applied for wireworm control. Agronomy Journal 99: 377-1381. 
Kerry BR, 2000. Rhizosphere interactions and the exploitation of microbial agents for the biological control of plant-parasitic nematodes. Annual Review of Phytopathology 38: 423-441.

Kim JJ, Goettel MS, Gillespie DR, 2007. Potential of Lecanicillium species for dual microbial control of aphids and the cucumber powdery mildew fungus, Sphaerotheca fuliginea. Biological Control 40: 327-332.

Kim JJ, Goettel MS, Gillespie DR, 2008. Evaluation of Lecanicillium longisporum, Vertalec ${ }^{\circledR}$ for simultaneous suppression of cotton aphid, Aphis gossypii, and cucumber powdery mildew, Sphaerotheca fuliginea, on potted cucumbers. Biological Control 45: 404-409.

Koske RE, 1982. Evidence for a volatile attractant from plant roots affecting germ tubes of a VA mycorrhizal fungus. Transactions of the British Mycological Society 79: 305310.

Krassilstchik J, 1888. La production industrielle des parasites végétaux por la destruction des insectes nuisibles. Bulletin Biologique de la France et de la Belgique 19: 461-472.

Langewald J, Kooyman C. 2007. Green Muscle ${ }^{\mathrm{TM}}$, a fungal biopesticide for control of grasshoppers and locusts in Africa. In: Vincent C, Goettel MS, Lazarovits G (Eds.), Biological Control: A Global Perspective. CABI International/AAFC, Wallingford, United Kingdom, pp. 311-318.

LeConte, JL, 1874. Hints for the promotion of economic entomology. Proceedings of the American Association for the Advancement of Science 22: 10-22.

Lee SM, Yeo WH, Jee HJ, Shin SC, Moon YS, 1999. Effect of entomopathogenic fungi on growth of cucumber and Rhizoctonia solani. Journal of Forest Science 62: 118-125.

Lewis WJ, van Lenteren JC, Phatak SC, Tumlinson III JH, 1997. A total system approach to sustainable pest management. Proceedings of the National Academy of Sciences USA 94: $12243-12248$.

Little AEF, Currie CR, 2008. Black yeast symbionts compromise the efficiency of antibiotic defenses in fungus-growing ants. Ecology 89: 1216-1222.

Luangsa-ard JJ, Hywel-Jones NL, Manoch L, Samson RA, 2005. On the relationships of Paecilomyces sect. Isarioidea species. Mycological Research 109: 581-589.

Meyling N, Pell JK, 2006. Detection and avoidance of an entomopathogenic fungus by a generalist insect predator. Ecological Entomology 31: 162-171. 
Meyling N, Eilenberg J, 2007. Ecology of the entomopathogenic fungi Beauveria bassiana and Metarhizium anisopliae in temperate agroecosystems: Potential for conservation biological control. Biological Control 43: 145-155.

Nikoh N, Fukatsu T, 2000. Interkingdom host jumping underground: phylogenetic analysis of entomopathogenic fungi of the genus Cordyceps. Molecular Biology and Evolution 17: 629-638.

Oerke, E-C, 2006. Crop losses to pests. Journal of Agricultural Science 144: 31-43.

Ormond EL, Thomas APM, Pell JK, Roy HE, 2006. Overwintering ecology of Coccinella septempunctata, Beauveria bassiana and Dinocampus coccinellae. IOBC wprs Bulletin 29: 85-88.

Ownley BH, Dee MM, Gwinn KD, 2008a. Effect of conidial seed treatment rate of entomopathogenic Beauveria bassiana 11-98 on endophytic colonization of tomato seedlings and control of Rhizoctonia disease. Phytopathology 98: S118.

Ownley BH, Griffin MR, Klingeman WE, Gwinn KD, Moulton JK, Pereira RM, 2008b. Beauveria bassiana: endophytic colonization and plant disease control. Journal of Invertebrate Pathology 98: 267-270.

Ownley BH, Pereira RM, Klingeman WE, Quigley NB, Leckie BM, 2004. Beauveria bassiana, a dual purpose biocontrol organism, with activity against insect pests and plant pathogens, In: Lartey RT, Caesar AJ, (Eds.), Emerging Concepts in Plant Health Management, Research Signpost, India, pp. 255-269.

Ownley BH, Windham M, 2007. Biological control of plant pathogens. In: Trigiano RN, Windham MT, Windham AS, (Eds.), Plant Pathology: Concepts and Laboratory Exercises, $2^{\text {nd }}$ ed. CRC Press, Boca Raton, Florida, pp. 423-436.

Pasteur L, 1874. Observations (au sujet des conclusions de M. Dumas) relatives au phylloxera. Comptes rendus hebdomadaires des séances de l'Académie des Sciences 79: 1233-1234.

Pereira RM, Stimac JL, Alves SB, 1993. Soil antagonism affecting the dose response of workers of the red imported fire ant, Solenopsis invicta, to Beauveria bassiana conidia. Journal of Invertebrate Pathology 61: 156-161.

Rangel DEN, Braga GUL, Anderson AJ, Roberts DW, 2005. Variability in conidial thermotolerance of Metarhizium anisopliae isolates from different geographic origins. Journal of Invertebrate Pathology 88: 116-125.

Reisenzein H, Tiefenbrunner W, 1997. Growth inhibiting effect of different isolates of the entomopathogenic fungus Beauveria bassiana (Bals.) Vuill. to the plant parasitic 
fungi of the genera Fusarium, Armillaria and Rosellinia. Pflanzenschutzberichte 57: 1524.

Renwick A, Campbell R, Coe S, 1991. Assessment of in vivo screening systems for potential biocontrol agents of Gaeumannomyces graminis. Plant Pathology 40: 524-532.

Roberts DW, Campbell AS, 1977. Stability of entomopathogenic fungi. Miscellaneous Publications of the Entomological Society of America 10: 19-76.

Roberts DW, Humber RA, 1981. Entomogenous fungi. In: Cole GT, Kendrick B, (Eds.), Biology of Conidial Fungi. Academic Press, New York, pp. 201-236.

Roberts DW, Aist JR (Eds.), 1984. Infection Processes of Fungi. A Bellagio Conference. March 21-25, 1983. The Rockefeller Foundation.

Roy HE, Steinkraus DC, Eilenberg J, Hajek AE, Pell JK, 2006. Bizarre interactions and endgames: entomopathogenic fungi and their arthropod hosts. Annual Review of Entomology 51: 331-357.

Rudgers JA, Holah J, Orr SP, Clay K, 2007. Forest succession suppressed by an introduced plant-fungal symbiosis. Ecology 88: 18-25.

Sabelis MW, Janssen, A, Pallini A, Venzon M, Bruin J, Drukker B, Scutareanu P, 1999. Behavioural responses of predatory and herbivorous arthropods to induced plant volatiles: From evolutionary ecology to agricultural applications. In: Agrawal AA, Tuzun S, Bent E (Eds.), Induced Plant Defenses Against Pathogens and Herbivores: Biochemistry, Ecology, and Agriculture. American Phytopathological Society, St. Paul, Minnesota, pp. 269-296.

Saikkonen K, Lehtonen P, Helander M, Koricheva J, Faeth SH, 2006. Model systems in ecology: dissecting the endophyte-grass literature. Trends in Plant Science 11: 428-433.

Schulz B, Boyle C, 2005. The endophytic continuum. Mycological Research 109: 661686.

Singh BK, Millard P, Whiteley AS, Murrell JC, 2004. Unravelling rhizosphere microbial interactions: opportunities and limitations. Trends in Microbiology 12: 386393.

Spatafora JW, Sung G-H, Sung J-M, Hywel-Jones NL, White Jr. JF, 2007. Phylogenetic evidence for an animal pathogen origin of ergot and the grass endophytes. Molecular Ecology 16: 1701-1711.

Staples JA, Milner RJ, 2000. A laboratory evaluation of the repellency of Metarhizium anisopliae conidia to Coptotermes lacteus (Isoptera: Rhinotermitidae). Sociobiology 36, 133-148. 
St Leger RJ, 2007. Genetic modification for improvement of virulence of Metarhizium anisopliae as a microbial insecticide. In: Vincent C, Goettel MS, Lazarovits G (Eds.), Biological Control: A Global Perspective. CABI International/AAFC, Wallingford, United Kingdom, pp. 328-335.

St Leger RJ, 2008. Studies on adaptation of Metarhizium anisopliae to life in the soil. Journal of Invertebrate Pathology 98: 271-276.

Strasser H, Abendstein D, Stuppner H, Butt TM, 2000. Monitoring the distribution of secondary metabolites produced by the entomogenous fungus Beauveria brongniartii with particular reference to oosporein. Mycological Research 104: 1227-1233.

Sung G-H, Hywel-Jones NL, Sung J-M, Luangsa-ard JJ, Shrestha B, Spatafora JW, 2007. Phylogenetic classification of Cordyceps and the clavicipitaceous fungi. Studies in Mycology 57: 5-59.

Tanada Y, Kaya HK, 1993. Insect Pathology. Academic Press, Inc., San Diego, USA.

Taylor JW, Berbee ML, 2006. Dating divergences in the Fungal Tree of Life: review and new analyses. Mycologia 98:838-849.

Thacker JRM, 2002. An Introduction to Arthropod Pest Control. Cambridge University Press, Cambridge, United Kingdom.

van Dam NM, Harvey JA, Wäckers FL, BezemerTM, van der Putten WH, Vet LM, 2003. Interactions between aboveground and belowground induced responses against phytophages. Basic and Applied Ecology 4: 63-77.

Vega FE, 2008. Insect pathology and fungal endophytes. Journal of Invertebrate Pathology 98: 277-279.

Vega FE, Posada F, Aime MC, Pava-Ripoll M, Infante F, Rehner SA, 2008. Entomopathogenic fungal endophytes. Biological Control 46: 72-82.

Vesely D, Koubova D, 1994. In vitro effect of entomopathogenic fungi Beauveria bassiana (Bals.-Criv.) Vuill. and Beauveria brongniartii (Sacc.) Petch on phytopathogenic fungi.Ochrana Rostlin 30: 113-120.

Vincent C, Goettel MS, Lazarovits G (Eds.), 2007. Biological Control: A Global Perspective. CAB International/AAFC, Wallingford, United Kingdom.

Waage J, 1998. The future development of IPM. Entomologia Sinica 5: 257-271.

Welsh R, Hubbell B, Ervin DE, Jahn M, 2002. GM crops and the pesticide paradigm. Nature Biotechnology 20: 548. 
Whipps JM, 2001. Microbial interactions and biocontrol in the rhizosphere. Journal of Experimental Botany 52: 487-511.

Wraight SP, Jackson MA, de Kock SL, 2001. Production, stabilization, and formulation of fungal biocontrol agents. In: Butt TM, Jackson CW, Magan N (Eds.), Fungi as Biocontrol Agents: Progress, Problems and Potential. CABI Publishing, Wallingford, United Kingdom, pp. 253-288 


\section{Figure Legends}

Figure 1. Phyla of fungi based on (Hibbett et al. 2007) indicate that Fungi are more diverse than previously appreciated. Major changes include separation of groups with flagellated cells (“Chytrids”) in three phyla and separation of zygosporic fungi (“Zygomycetes”) in at least three lineages. Numbers of described fungal phyla from Kirk et al. (2008) and for the outgroup from The IUCN Red List of Threatened Species (http://www.iucnredlist.org/static/stats, Table 1).

Figure 2. Phylogenetic tree showing interkingdom host jumping among members of Hypocreales. Stalked stromata among sexually reproducing, animal parasitic taxa are the result of convergent evolution, and acquisition of a well resolved phylogeny has resulted in numerous taxonomic changes at family and generic level, some of which are shown on the tree; clades a-c are identified as originally published (Spatafora et al. 2007, http://cordyceps.us/Systematics ). Note especially the restricted use of Cordyceps, and new names Elaphocordyceps and Ophiocordyceps. 


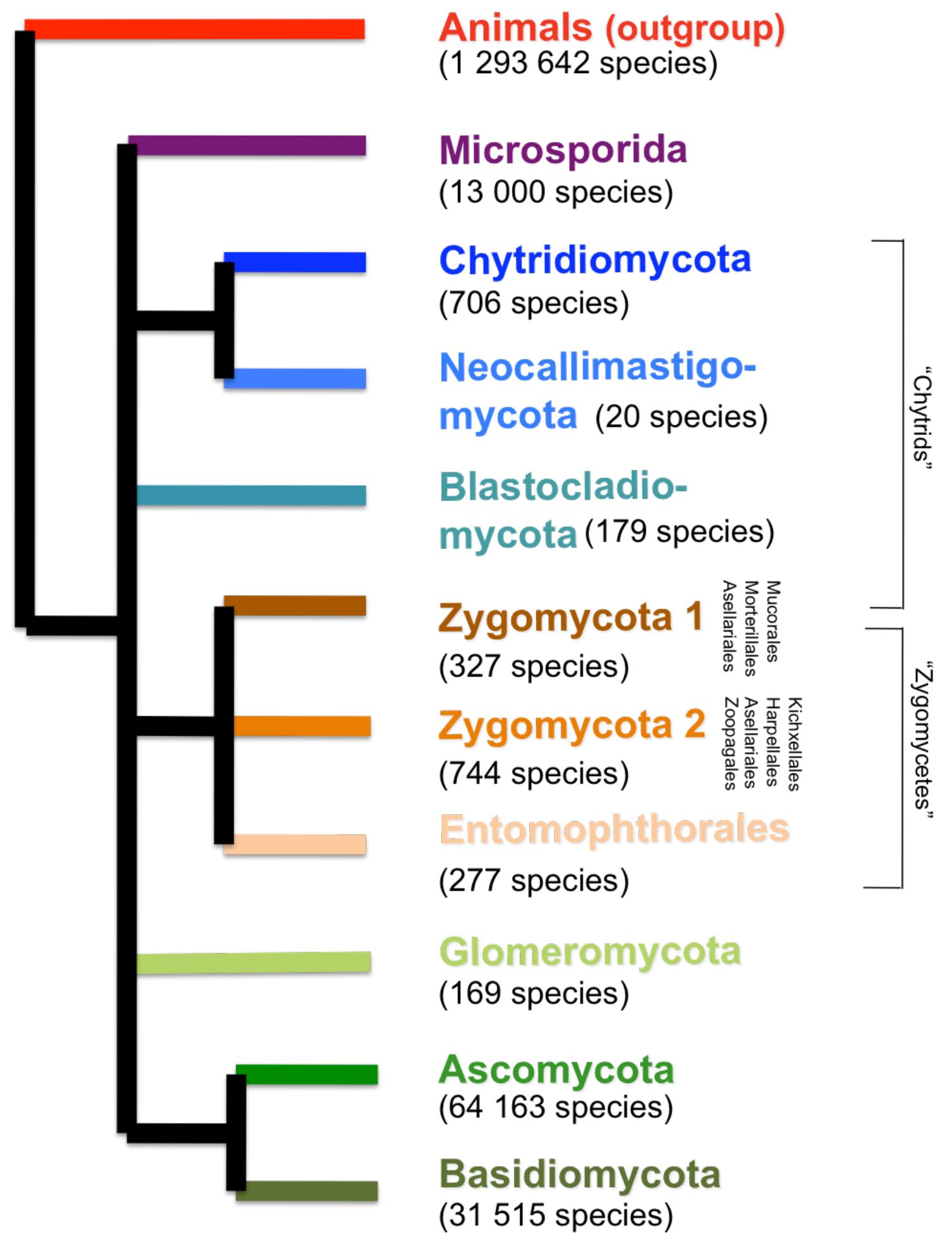



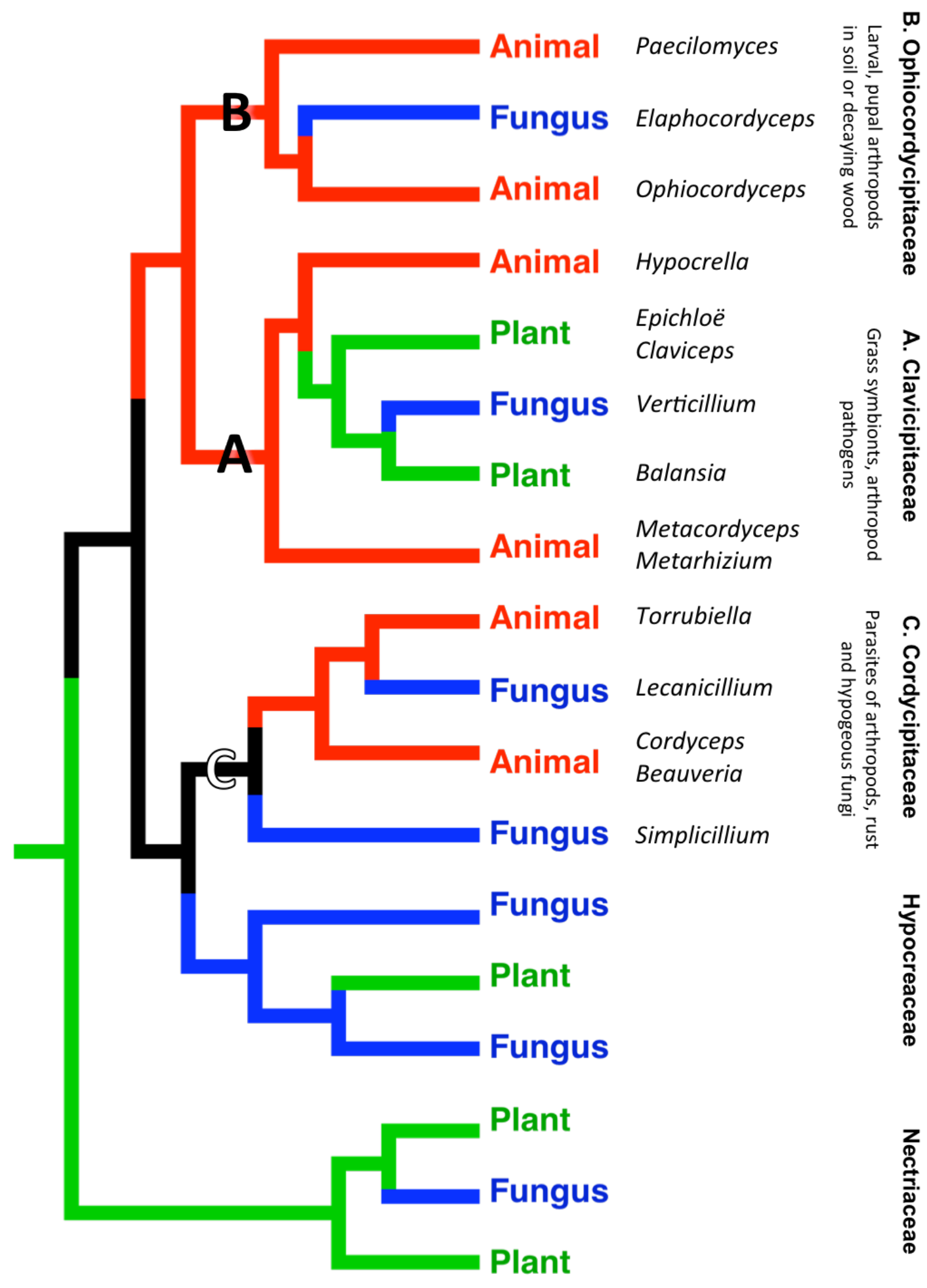

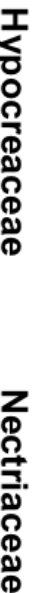

